\title{
Employee Benefits Consulting: An Essential Role for Pharmacy
}

\author{
B y C o n n i e P e r r y
}

$\mathrm{E}$ mployers today face a complex assortment of health care decisions as employees clamor for expanded benefits and the cost of health care continues to grow. The pharmacy benefit, although one of the most desirable for employees, is financially a high risk for payors. The role of the pharmacy benefits consultant has grown to match employers' needs; it now includes not only review of medication expenditures but also analysis of the overall health care plan design and increased use of clinical programs to optimize medical and pre scription-drug management.

The importance of good benefits consulting can be underscored by some recent cost trends. In the early 1980 s, prescription drugs accounted for about $2.3 \%$ of the U.S. health care dollar. That figure grew to $10 \%$ in the early $1990 \mathrm{~s}$, and to $15 \%$ by $2000 .{ }^{1}$ Clients outside of a managed care plan experienced higher annual increases (about $18 \%)$ than did managed care clients (approximately 16.3\%).2 Clearly, drugbenefit management has had an impact.

During the next five years, double-digit annual increases are expected. ${ }^{1}$ It is commonly accepted that the cost of the prescription benefit will only be curbed if a clinical consulting approach is used when pharmacy benefits are introduced or refined. This represents an opportunity for managed care pharmacists to have considerable impact on the cost and quality of health care.

\section{†t History Is Important}

Managed care has arrived at this point as the natural consequence of its history. Managed care is a form of insurance. Until W orld War II (WWII), health insurance was a fringe benefit, meaning it was an optional incentive to attract and retain employees. During WWII, wages were frozen but benefits were not. Consequently, the health care benefit as a form of compensation moved from the fringe into the limelight. ${ }^{3}$ The government provided incentives to promote employee benefit plans, including tax laws favoring businesses that provided health insurance.

Over the next two decades, fee for-service health care flourished, and the cost of health care was unfettered. Benefits that were once considered optional or attractivepharmacy, dental, and vision- becamehighly desirable to employees, and pressure to make them standard offerings increased. By the 1960s, health care financing had become a national concern, and various methods of controlling costs were introduced.

From the inception of managed care, performance benchmarks focused on cost savings, not clinical outcomes. ${ }^{4}$ Plan designs assumed that providers would manage insurable risk to maximize outcome and minimize complications at a rea sonable cost. ${ }^{3}$ In the 1980 s, pharmacy benefit management relied on controlling unit cost and unit utilization. How successfully managed care principles were applied depended on a number of factors. The ini- tial cost containment began to level out in the 1990s.

Today, there are concerns about quality of care, member satisfaction, and breadth of coverage as well as cost. Thus, health care plans must use cost manage ment as a foundation, use managed care principles to design benefits, use a delivery system based on quality-management principles, and comply with numerous laws. For the pharmacy benefit today, three factors are essential:

- controlling unit cost and utilization;

- sharing financial risk (and some decision making) by having members pay a nominal fee whenever they access the health care system; and

- obtaining discounts from all providers and vendors that influence drug costs.

The complexities of drug therapy, the entry of cosmetic and life-enhancing medications, new product pricing, and clinical program opportunities have all affected medication use and opened new venues for benefit management. Pharmacy-benefit consulting must give history its due, use today's tools efficiently, and look to the future to anticipate changes on both the immediate and the distant horizons.

\section{\pm Who Manages the Benefit?}

Employers have options when evaluating cost drivers in their populations. They can use a third-party administrator, their medical insurance carrier, or a pharmacy

\section{Author}

CONNIE PERRY, Pharm.D., is Assistant Vice President, Aon Consulting, Inc., Chicago, IL.

AUTHOR CORRESPON DEN CE: Connie Perry, Pharm.D., Assistant Vice President, Aon Consulting, Inc., 123 North Wacker Dr., Suite 1000, Chicago, IL 60606-1770;

Tel.: 312-701-3695; Fax: 312-701-4855; E-mail: connie_f_perry@aoncons.com.

Copyright@ 2001 Academy of M anaged Care Pharmacy, Inc. All rights reserved. 


\begin{tabular}{l}
\hline TA B LE 1 Pharmacy Cost \\
Drivers in 2001 \\
\hline - Aging population \\
\hline - Explosion of new drugs \\
\hline - Medical guidelines specifying earlier drug \\
interventions \\
\hline - N ew, multidrug regimens \\
\hline - N ew treatments for previously untreatable \\
diseases \\
\hline - Better patient compliance \\
\hline - Direct-to-consumer advertising \\
\hline - Price inflation
\end{tabular}

larly helpful when employers request additional clarification on current pre scription drug benefit issues.

Defining what a pharmacy benefits consultant does is difficult. Table 2, below, shows several definitions. While the general duties can be specified, how they are performed varies. Often, information about benefit management is not available because it is proprietary to the companies that own it. ${ }^{3}$

In general, consultants use two techniques to manage the benefit: economic techniques (plan design) and benefit management (clinical tools). Three unique functions pharmacy consultants perform today

TAB LE 2 What Pharmacy Benefit Consultants Can Do

Pharmacy benefit consultants:

\begin{tabular}{l} 
- Control costs by managing unit cost (price) and number of units used (quantity or \\
utilization) \\
- Introduce or recommend enhancements to tools and techniques to manage the \\
prescription benefit \\
- Design and implement organizational activities to influence prescriber, pharmacist, and \\
patient behavior in such a way that the cost and use of prescription coverage is decreased \\
\hline
\end{tabular}

benefits management company (PBM). Regardless of which they select, employers expect recommendations based on data and reports that respond directly to the issues in ways that are easily understood and supportable.

These reports can serve as tools to educate employers on what drives costs in today's market (see Table 1, above). Tom Lerche, health and welfare practice leader at Aon Consulting, describes the pharmacist's role succinctly: "Our customers are self-funded employers who find that the prescription drug benefit is one of their top three problems. This is a difficult area because it is high cost, but of high value to employees. Pharmacists bring to bear clinical knowledge and skills. ${ }^{15}$ He then demonstrates that disease management is a cousin to the drug benefit, and that when a consulting pharmacist is able to apply disease-management theories creatively, the customer benefits. These pharmacists are particu- are (1) evaluation and analysis of the bene fit, comparing it with national cost trends; (2) guiding the proposal and marketing processes; and (3) auditing vendors.

$t+$ Evaluating the Pharmacy Benefit Evaluating the pharmacy benefit requires simultaneous analysis of the financial and clinical techniques employed.

Financial areas include member costsharing, the exclusion medication list, retail and mail service pricing and fees, use of generic medication, formulary analysis, and rebate/discount arrangements. Despite their designation as financial, each of these areas can be addressed better if the pharmacist's inherent clinical insight adds perspective. For example, though the decision to change from a two-tier to a threetier cost-share affects members, the impact can be mitigated if sound clinical judgment is used to determine where drugs are placed in the tiers.

Research has confirmed that current cost drivers in pharmacy include increased drug use by members, with a changing mix of drugs contributing approximately equally and inflation contributing less. ${ }^{1,6}$ Reasons for increased use include an aging popula tion, new prescribing guidelines that emphasize combination therapy, a plethora of new therapeutic drug advances, increased compliance among members, and pharma ceutical company advertising (both directto-consumer and to providers).

Clinical program opportunities abound: retrospective, concurrent, or prospective drug-utilization review; prior-authorization protocols; provider profiling; and wellness or disease-management programs. Clearly, implementing these programs can reduce costs and minimize the need to increase member cost share.

Pharmacy consultants have learned several lessons over the decades:

- Introducing several changes at once is likely to be less successful than introducing changes gradually with ample communication to and lead-time for affected parties. ${ }^{6}$

- Analysis of plan design should start with the member cost-share to ensure that it is appropriate, encourages use of generics and mail-in programs, and addresses cosmetic, life-enhancing, or discretionary drugs in a way that is fair and humane.

- Pharmacy benefits consultants should and can successfully address utilization, affecting cost significantly.

- Excluding drugs after they have been approved and have gained users creates discontent among providers and members; each new drug choice should be analyzed well before its introduction to the market.

- Formularies can promote step care, limiting inclusion only to those doses and delivery forms that are most cost-effective. ${ }^{1}$ Measuring the pharmacy benefit against regional standards, reconciling employer human resource strategy and employee need, integrating clinical and financial processes, and anticipating new drugs before they enter the market place together create the best foundation for cost-effective, high-quality care. 
Employee Benefits Consulting: An Essential Role for Pharmacy

TA B LE 3 Core Performance Measures

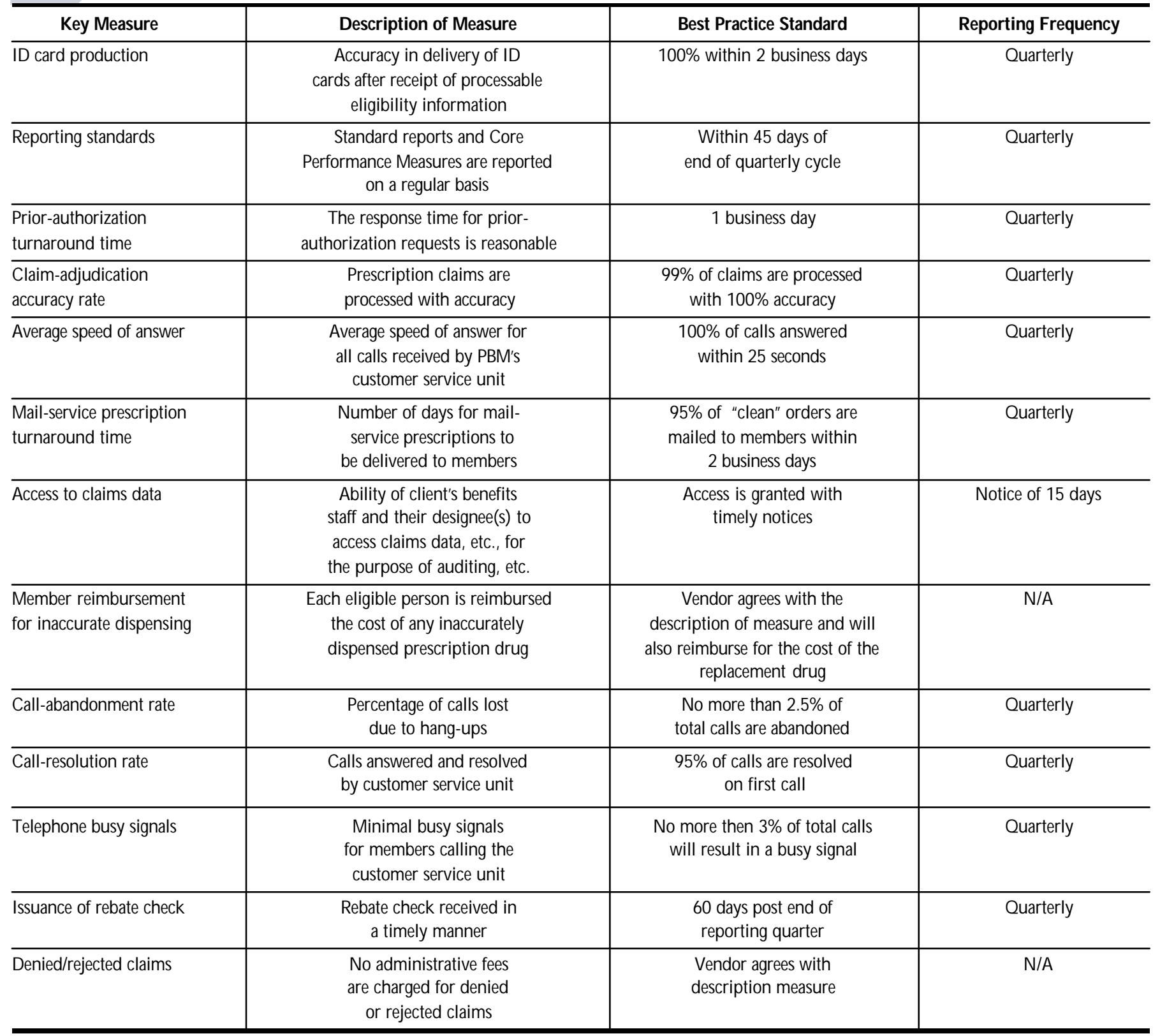

\section{$\pm t$ The Proposal Process}

Among the pharmacy benefit consultant's most popular projects is the request for proposal (RFP) or vendor marketing and selection process. Pam Hodge, an assistant vice president with Aon Consulting, suggests bringing in a pharmacy consultant whenever a client requests a prescription drug study. Her clients are generally interested in a long-term strategy for controlling prescription drug costs. These strategies may include plan redesign, employee education, a common formulary approach, and negotiating rebates and lower administrative costs with vendors. She has found that the expertise of a pharmacy benefits consultant can be helpful to clients in designing and executing these strategies.

Selecting the best vendor to meet an employer's needs can be challenging today.
Legal, clinical, and business changes in health care have created an environment in which complex plan designs, superior account management, and performancemeasurement agreements are the rule rather than the exception. This complicates the proposal process. In the past, fee or discount negotiation often gave the complete answer to an employer's cost concerns. Today, clinical issues abound, and performance meas- 


\section{TA B LE 4 Elements of a Database Audit}

- Analyze manufacturer rebates and their application to client

- Identify apparent duplicate claim payments

- Identify prescribing/utilization patterns within specific therapeutic categories

- Analyze formulary alternatives used and the formulary-conversion process

- Identify generic fill rate

- Validate eligibility updating and procedures for terminations and additions

- Validate claim-system edits for plan limitations, maximums, and prescription preauthorizations

- Analyze for possible fraudulent, drug abuse, or misuse-related claims

- Validate pharmacy reimbursement rates and accuracy of claim payments

- Evaluate impact of retail versus mail reimbursement formulas (if applicable)

ures must be incorporated to address customer service concerns. In addition, member access to services must be considered.

One state-government manager commented after working with a pharmacy benefits consultant to develop an RFP for a 100,000-member program: "Any organiza tion that is going through the painful task of looking at prescription drugs is bombarded with information from lobbyists, vendors, and other interested parties. They all have an interest in the outcome. Having a pharmacy benefits consultant helps us direct our energies appropriately."

Table 3, page 270, describes some current performance measures that define the employer, provider, and consumer expecta tions of acceptable service. Too often the community pharmacist is swamped with problems when new identification cards should have been mailed but were not, the physician is frustrated with prior approval delays, or the member's prescription arrives after several doses have been missed. Incorporating performance measures into contracts improves the quality of service by clarifying tasks, time frames, appropriate measures, and reporting frequencies. Performance, however, must be measured with both the client's or business environment's perspective and accepted or pending mitigating factors in mind.

\section{$\ddagger \ddagger$ Vendor Audits}

Vendor audits ensure quality service. They determine the effectiveness of vendor per- formance and compliance with contracts.

Audits are necessary because benefits managers and pharmacy directors may not always have the capability or documentation to verify certain aspects of service. For example, rebate amounts are based on volume of product sold; an audit can determine if the rebate was appropriate to the volume sold. Also, key performance measures can be audited to ensure that they are being met. In short, almost anything-financial or clinicalcan be audited.

Table 4, above, describes the basic ele ments of an audit. Audits generally rely on review of databases. Once the audit is conducted, the pharmacy consultant must report findings and make recommendations for corrective actions. These recommenda tions may include changes to the PBM agreement or benefit plan. The report must also document any variances in terms of billing errors or overpayments and describe trends or specific areas where new process es can prevent future problems.

† Implications for Managed Care Pharmacists

The average employee benefit package consumes $30 \%-50 \%$ of employer payroll costs, yet it is a source of dissatisfaction and skepticism for many employees. ${ }^{3}$ The drug benefit has come to be considered more of an entitlement than an option for many. Many studies have shown that drug therapy is often the most-effective and least-expensive form of treatment. With its increasing importance, the pharmacy benefit will continue to be scrutinized, changed, and audited.

Managed care pharmacists must recognize that their information and clinical management functions will grow in significance. The consultant pharmacist who provides good data and sound clinical judgment will gain more opportunity to demonstrate how employers can contain costs and optimize medication use in the populations they serve.

\section{$t \oplus$ Conclusion}

Pharmacists working with health care plans should work with the plan's marketing department to ensure that employers understand the pharmacy-management programs used. Meeting face-toface with employers is an excellent way to facilitate accurate communication.

As pharmacy benefits grow in importance, there will be more opportunity in the benefit-consulting field. Pharmacists with managed care experience, gained from employment with either a health plan or a PBM, will be ideal candidates for these positions. In this way, the effect of managed care on health care will continue to expand.

\section{References}

1. Disease management: Next step in managed care. Aon Consulting Forum, December 1999-January 2000.

2. Express Scripts. Drug trend report. St. Louis: Express Scripts, 1999; 1-51.

3. Stern CS. The history, philosophy, and principles of pharmacy benefits. J Managed Care Pharm 1999; 5(6): 525-31.

4. Wertheimer Al, Navarro RP. Pharmacy benefit management principles and practices. In: Managed care pharmacy practice: Principles and practice. New York: Pharmaceutical Products Press, 1999: 29-46.

5. Regulatory developments. Aon Consulting Forum. December 1999.

6. Merck-Medco. Managing pharmacy benefit costs, new insights for a new century, 2000 edition. www.merckmedco.com, accessed January 13, 2001. 